\title{
THE ETHNOPEDAGOGY STUDY ON THE "MEGIBUNG" TRADITION IN KARANGASEM
}

\author{
Luh Sri Kasih ${ }^{1}$, Gede Wira Bayu ${ }^{2}$, I Nyoman Laba Jayanta ${ }^{3}$ \\ ${ }_{1}^{1}$ Prodi Akuntansi, STIE Satya Dharma Singaraja, Indonesia \\ 2,3 Pendidikan Guru Sekolah Dasar, Universitas Pendidikan Ganesha Singaraja, Indonesia \\ E-mail: srigung17@yahoo.com ${ }^{1}$, wira.bayu@undiksha.ac.id ${ }^{2}$, laba.jayanta@undiksha.ac.id ${ }^{3}$
}

\begin{abstract}
Abstrak
Bali dikenal dengan budaya dan adat istiadatnya. Setiap lini kehidupan di Bali terkait dengan adat dan budaya termasuk pada prosesi "makan bersama" atau yang dikenal dengan istilah "mengibung". Tradisi megibung di Bali sudah ada sejak jaman perang sekitar tahun 1614 Caka atau saat Raja Karangasem I Gusti Anglurah Ktut Karangasem, berperang menaklukkan kerajaan-kerajaan di Sasak (Lombok). Pada saat itu "megibung" dilaksanakan untuk menjaga persatuan dan kekompakan pasukan saat berperang dengan makan bersama. Tradisi "megibung" sebenarnya sarat akan makna dan aturan. Dalam tulisan ini, penulis berusaha mengkaji tradisi "megibung" dalam kajian etnopedagogik dengan berusaha mengkaji nilai filosofis, antropologis, sosiologis dan psikologis yang terdapat pada tradisi "megibung".
\end{abstract}

Kata Kunci: "Megibung"; Ethnopedagogy

\begin{abstract}
Bali is known for its culture and customs. Every line of life in Bali related to customs and culture, including the procession of "eating together" or known as "mengibung". The "megibung" tradition in Bali dates back to the war around 1614 Caka or when Raja Karangasem I Gusti Anglurah Ktut Karangasem, fought to conquer kingdoms in Sasak (Lombok). At that time "megibung" was carried out to maintain the unity and cohesiveness of the forces while fighting with eating together. The "megibung" tradition is actually full of meaning and rules. In this paper, the author attempts to examine the tradition of "megibung" in ethnopedagogic studies by trying to examine the philosophical, anthropological, sociological and psychological values found in the "megibung" tradition.
\end{abstract}

Keyword: "Megibung"; Ethnopedagogy

\section{Pendahuluan}

Banyak tradisi yang ada dalam masyarakat di Bali hanya dilaksanakan secara turun temurun menurut kebiasaan dengan ditandai dengan seringnya kita mendengar kalimat "anak mule keto" jika ditanya tentang arti dari suatu tradisi yang dilaksanakan. Hal ini sering menjadi kelemahan dari keberlangsungan tradisi tersebut karena generasi yang berikutnya hanya melaksanakan suatu tradisi tanpa didasari dengan makna dan maksud dari tradisi tersebut sehingga generasi tersebut kurang memiliki semangat dari pelaksanaan tradisi yang diikuti atau dilakukan.

Salah satu tradisi yang masih sering dilaksanakan pada keseharian masyarakat bali adalah tradisi makan bersama yang dikenal dengan istilah "megibung". Dewasa ini Tradisi "megibung" biasanya dilakukan setelah selesainya suatu prosesi keagamaan berupa piodalan. Namun sebenarnya banyak sekali generasi yang mengikuti proses tradisi "megibung" tanpa mengetahui makna nilai dari "megibung" itu sendiri. Dalam kesempatan ini penulis ingin mengkaji tradisi "megibung" secara etnopedagogi untuk memperoleh gambaran tentang nilai filosofis, antropologis, sosiologis dan psikologis yang terdapat di dalam tradisi "megibung" tersebut.

\section{Metode}

Penulisan artikel ini menggunakan study literature. Data mengenai nilai-nilai tradisi Megibung ditelaah melalui referensi dan artikel yang terkait. Telaah penelitian sejenis juga dilakukan untuk mendapatkan simpulan yang akurat. 


\section{Hasil dan Pembahasan Etnopedagogi}

Ide tentang etnopedagogi di Indonesia muncul di kampus UPI melalui pemikiran Alwasilah,et.al (2009) dan Kartadinata (2010). Istilah etnopedagogi di UPI menurut Suratno (2010) dapat dipandang sebagai suatu pesan terkait dengan dengan istilah budaya-karakter (aspek etno), dan pendidikan keguruan (aspek pedagogi).

Alwasilah, et.al (2009) mengemukakan dalam konteks budaya secara umum, etnopedagogi menaruh perhatian khusus terhadap local genius danlocal wisdom dengan mengungkap nilai-nilai budaya Sunda sebagai model awal. Ajip Rosidi (2009) mengingatkan bahwa nilai budaya Sunda modern telah berbaur dengan budaya lainnya. Beberapa postulat dikemukakan terkait karakter masyarakat Sunda: hurip, waras, cageur, bageur, bener, pinter, ludeung, silih asah, silih asuh, silih asih, sineger tengah, singer, motekar dan rapekan ( Kartadinata, 2010). Dapat dikatakan bahwa Etnopedagogi memandang pengetahuan atau kearifan lokal (local knowledge, local wisdom) sebagai sumber inovasi dan keterampilan yang dapat diberdayakan demi kesejahteraan masyarakat

Dalam perspektif hakikat pendidikan, baik Alwasilah et al. (2009) maupun Kartadinata (2010) memandang bahwa pendidikan tidak terlepas dari aspek sosial dan kultural. Pendidikan bersifat deliberatif dalam arti masyarakat mentransmisikan dan mengabadikan gagasan kehidupan yang baik yang berasal dari kepercayaan masyarakat yang fundamental mengenai hakikat dunia, pengetahuan dan tata nilai (Alwasilah et al., 2009). Oleh karena itu, diperlukan reorientasi landasan ilmiah mengenai pendidikan yang hirau terhadap nilai-nilai kemanusiaan, sesuatu yang selama ini luput dari perhatian dikarenakan kurangnya studi tentang landasan budaya pendidikan. Keutamaan pendidikan hendaknya jangan sampai tereduksi menjadi hal-hal yang superficial, sebagaimana terjadi kini pada rezim standarisasi, sehingga mengabaikan tujuan luhur dari pendidikan itu sendiri, yaitu pendidikan yang membudayakan (Suratno, 2010).

Berdasarkan analisis terhadap dimensi budaya dan pendidikan, Alwasilah et al. (2009, Suratno,2010) memandang Etnopedagogi sebagai praktik pendidikan berbasis kearifan lokal dalam berbagai ranah serta menekankan pengetahuan atau kearifan lokal sebagai sumber inovasi dan keterampilan yang dapat diberdayakan demi kesejahteraan masyarakat, yakni kearifan lokal tersebut terkait dengan bagaimana pengetahuan dihasilkan, disimpan, diterapkan, dikelola dan diwariskan.

Etnopedagogi sebagai praktik pendidikan berbasis kearifan lokal nampaknya sejalan dengan temuan Alexander (2000, dalam Suratno, 2010) yang menunjukkan terdapat hubungan yang erat antara pedagogi dengan kehidupan sosial budaya masyarakatnya. Hal demikian juga sejalan dengan pandangan Bernstein (Bernstein \& Solomon, 1999, dalam Suratno, 2010) yang menyatakan "How a society selects, classifies, distributes, transmits and evaluates the educational knowledge it considers to be public, reflects both the distribution of power and principles of social control'.

Menarik apa yang dikemukakan oleh Suratno (2010) tentang upayanya untuk memposisikan etnopedagogi secara lebih strategis, pertama, etnopedagogi dapat berperan dalam pendidikan berbasis nilai budaya bagi pengajaran dan pembelajaran dalam konteks teaching as cultural activity (Stigler \& Hiebert, 1999) dan the culture of teaching. Di sisi lain, etnopedagogi berperan dalam menciptakan secara berantai kader-kader yang memiliki kecerdasan kultural dan konteks pendidikan guru.

Oleh karena diperlukan tindakan untuk mengangkat kembali nilai-nilai kearifan lokal sebagai sumber inovasi dalam bidang pendidikan berbasis budaya masyarakat lokal, dengan cara melakukan pemberdayaan melalui adaptasi pengetahuan lokal, termasuk reinterpretasi nilainilai kearifan lokal, dan revitalisasinya sesuai dengan kondisi kontemporer. Selain itu diperlukan kerjasama yang kuat antara pemerintah daerah, perguruan tinggi dan budayawan untuk revitalisasi nilai-nilai kearifan lokal maupun mengembangkan konsep-konsep akademik, melakukan uji coba model-model etnopedagogi dalam pembelajaran (Anan-Nur, 2010).

\section{Tradisi "Megibung"}

Bali sangat terkenal dengan tradidi dan budayanya yang sarat akan nilai-nilai moral, agama dan pendidikan. Banyak tradisi tercipta dibali untuk mempererat rasa persaudaraan dan memperkokoh persatuan. Salah satu tradisi tersebut adalah acara makan bersama yang dikenal dengan nama "megibung". Megibung merupakan tradisi makan bersama dalam satu wadah 
dengan cara lesehan posisi duduk melingkar yang biasanya berjumlah delapan orang. Adapun keunikan tersendiri dari tradisi megibung tersebut adalah laki-laki megibung bersama laki-laki. Sedangkan yang wanita bersama-sama dengan wanita. Peserta megibung tak harus dengan orang-orang yang saling dikenal. Para undangan yang tak saling kenal pun duduk dan makan bersama-sama. Sajian yang disantap bersama, namanya gibungan yang terdiri atas nasi yang dibulatkan lalu disajikan di atas dulang. Gibungan dilengkapi berbagai jenis masakan khas Bali dari babi, kecuali gibungan yang tidak boleh terbuat dari kerbau atau bebek.

Tanda mulainya megibung, diawali dengan memukul kentongan. Begitu tung, tung, tung, keluarga yang memiliki hajatan mempersilakan para undangan mendekat ke tempat gibungan yang telah disediakan. Biasanya gibungan ditempatkan di halaman rumah, atau tempat yang lapang, karena jumlahnya banyak dan agar bisa serentak. Gibungan itu, ditaruh di atas alas tikar atau daun pisang. Peserta megibung boleh tak beralas, namun gibungan harus dialasi. Penghormatan kepada Dewi Sri. Bagian yang juga harus ada dalam megibung selain gibungan, adalah ceretan (tempat air minum) dan paselokan (tempat cuci tangan).

Bila para undangan sudah mendekati gibungan, tukang tarek mulai memandu jalannya megibung. Mula-mula ditanyakan, apakah pesertanya sudah pepek (penuh delapan orang). Jika kurang ditambah agar jumlahnya lengkap delapan orang. Bila sudah pepek, tukang tarek mempersilakan peserta megibung mencuci tangan. Setelah usai cuci tangan, peserta megibung harus menunggu aba-aba dari tukang tarek. Setelah semua sudah cuci tangan, kemudian para undangan dipersilakan mulai makan dan para undangan serentak mulai menikmati hidangan bersama.

Setelah rangkaian megibung selesai, peserta tidak langsung bubar melainkan kembali mencuci tangan untuk megibung sanganan yang terdiri atas berbagai jenis jajan. Biasanya megibung sanganan dibarengi dengan menyajikan brem. Setelah megibung selesai, peserta tak boleh langsung bubar. Tukang tarek mempersilakan kembali cuci tangan. Gibungan yang tadinya terbuka, oleh peserta dilipat kembali. Setelah itu, peserta baru dipersilakan bubar.

\section{Nilai Filosofis Tradisi "Megibung" di Karangasem}

Berdasarkan informasi yang penulis himpun dari beberapa sumber dijelaskan bahwa tradisi megibung muncul dari para petani yang bekerja di sawah dengan nakil (membawa makanan dari rumah) dan kemudian makan bersama dengan petani-petani tetangganya yang juga nakil. Kegiatan tersebut terus dilakukan secara terus menerus pada lahan kosong di perbatasan petak sawah untuk kebersamaan para petani tersebut. Makan bersama dengan format yang lebih besar disebut megibung. Karena formatnya besar, maka acara megibung tidak bisa dilakukan di tengah persawahan atau di bawah pohon kopi yang rindang. Makanan untuk megibung dipersiapkan bersama-sama. Setelah makanan jadi, makanan ditaruh dalam sebuah tempat besar, lalu dikitari beberapa orang.

Tradisi megibung (makan bersama) diciptakan oleh Raja Karangasem, I Gusti Anglurah Ktut Karangasem ketika beliau menyerbu Lombok. Megibung digunakan untuk menghitung korban perang dan pasukan yang masih bertahan. Megibung memberi penekanan pada nilai kebersamaan dan demokrasi. Tidak ada perbedaan kasta dan perbedaan tingkat ekonomi, semua orang yang mengelilingi gibungan adalah sama di hadapan Dewi Sri (Dewi Kemakmuran). Tradisi ini adalah implementasi dari filosofi Bali kuno, "paros sarpanaya, selunglung sabayantaka" atau kebersamaan dalam suka dan duka. (Bali Indonesia Travel Guide)

\section{Nilai Antropologis dalam Tradisi Megibung}

Tradisi megibung diselenggarakan dengan tujuan membangun rasa kebersamaan dan kekuatan dari persahabatan dan persaudaraan. Semua peserta megibung adalah sama, tidak ada yang kaya atau miskin dan tidak ada yang berpendidikan maupun yang tidak berpendidikan. Jelas bahwa ketika peserta megibung duduk dan makan dalam satu tempat, tidak ada lagi perbedaan kedudukan, status sosial, maupun status pendidikan. (terjemahan dari Bali Travel News)

Megibung adalah tradisi makan bersama yang unik, yang merupakan suatu wadah kebersamaan dalam suatu lingkungan sosial, yang di dalamnya rasa suka duka melebur menjadi satu (www.karangasemtourist.com).

Menurut Menteri Kebudayaan dan Pariwisata, Jero Wacik (2006) "megibung" yang merupakan salah satu unsur budaya yang tumbuh di Pulau Dewata, perlu terus dikembangkan dan didukung keberadaannya oleh semua pihak. Melalui kegiatan "megibung" akan banyak dapat dipetik makna filosofi yang mendalam, karena di dalam kegiatan itu selain terkandung unsur 
kebersamaan, juga disiplin dan kekerabatan. (diterjemahkan dari Travel News Thu, 28 Dec. 2006)

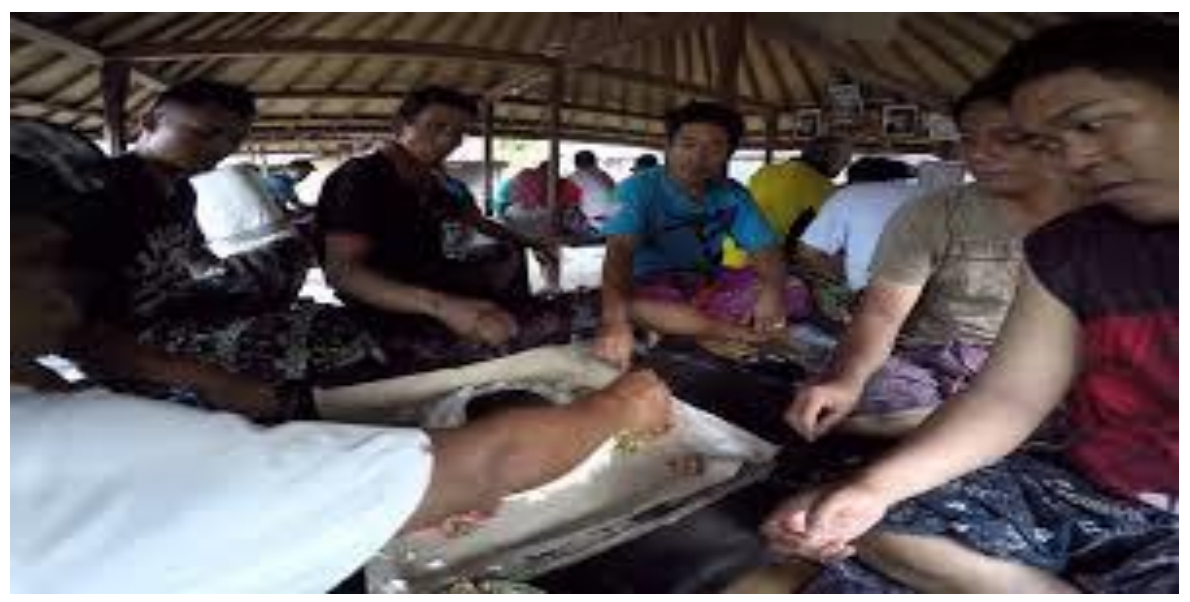

Gambar 1 Tradisi Megibung di Karangasem

Gambar 1 menggambarkan tradisi megibung memiliki nilai kebersamaan, disiplin, dan kekerabatan. Budaya megibung (makan bersama) yang masih bertahan di Karangasem, sementara di daerah lain sudah dipunahkan oleh cara makan prasmanan. Filsafat megibung sungguh tinggi, makan bersama tak mengenal tingkatan orang dari materi atau kedudukan bisa makan bersama dengan aturan yang dipatuhi peserta makan. Seperti lawar dari berbagai jenis menjadi satu, menimbulkan rasa lawar yang enak. Begitulah hendaknya masyarakat melihat perbedaan jenis dan warna, jika disatukan bakal menjadi enak. (Amlapura (Bali Post) Pesan Ida Pedanda Made Gunung)

Ada yang unik dalam tradisi ini, yang dilakukan oleh umat non Hindu. Beberapa umat Muslim di Bali, makan bersama dalam satu wadah (megibung) dalam perayaan Maulid Nabi Muhammad Saw. Seperti layaknya umat muslim di seluruh dunia, umat muslim di Pulau Dewata Bali, juga memperingati Maulid Nabi Muhammad Saw dengan meriah, Sabtu (31/3) kemarin. Meski di Pulau Dewata, penganut agama Islam merupakan minoritas, perayaan maulid tetap dilangsungkan. (Metrotvnews.com, Denpasar: 2007) Seperti yang dilakukan umat muslim di Kampung Islam Kepaon, Denpasar. Warga mempunyai tradisi merayakan Maulid Nabi dengan menggelar tradisi Mengibung atau makan bersama dalam satu wadah. Makan bersama ini dilakukan di dalam masjid setempat, yang sebelumnya telah dihias beragam pohon berhias telur serta diberi lapisan kertas warna warni.

Dengan demikian nilai antropologis yang dapat kita ambil dari tradisi "megibung" ini adalah kebersamaan, disiplin dan kekerabatan yang dapat diimplementasikan tidak hanya oleh umat Hindu Bali tetapi juga umat Muslim yang ada di Bali.

\section{Nilai Sosiologis dalam Tradisi Megibung}

Persiapan untuk acara megibung ini untuk di Bali dikerjakan bersama secara gotong royong oleh warga banjar, tetangga atau undangan terdekat. Biasanya dikerjakan sejak sehari sebelum hari $\mathrm{H}$. Dari menangkap babi, ayam atau kambing, membuat bumbu, lanjut mengerjakan samapi selesai pada hari $\mathrm{H}$ tersebut. Yang dibuat jenis-jenis lauk pauk tersebut diantaranya: lawar, kekomoh, nyuh-nyuh putih, nyuh-nyuh barak, padamara, wilis (bahannya dari daun belimbing), kacang-kacang, marus, urutan, sate, timbung (rawon), balah dll. Satenya juga banyak macam seperti sate lembat, pusut, asem, kablet dan obob. Setelah seluruhnya selesai, diatur pada satu tempat gelaran (anyaman daun kelapa muda) sedemikian rupa lengkap segala jenis tersebut di atas serba sedikit untuk porsi 8 orang laki-laki atau 10 orang wanita. Jumlah satenya biasanya 15 sampai 20 tangkai. Satu gelaran atau satu porsi ini bernamakan Sela/Gibungan. Ada juga diantaranya bertugas memasak nasi, nasi diatur menjadi gibungan. Gibungan dimaksud adalah nasi seberat satu kilogram diatur diatas gelaran, dialasi dengan nampan, nare atau baki, ada juga yang memakai dulang (lihat foto) dimana pada pinggirnya ditaruh garam atau sambal secukupnya. Pada hari $\mathrm{H}$ apabila segala persiapan telah selesai, mulai pukul sembilan acara megibung digelar, kadang kala kalau tamu banya acara ini digelar sampai 3 atau 4 periode, dimana satu periode samapai 20 sela (gibung/rombongan). Gibungan diatur penempatannya berbaris, dibedakan tempatr untuk tamu wanita dan laki-laki. Di sebelah masing-masing gibungan 
tersebut juga disiapkan karangan, air cuci tangan, kendi tempat air minum. Demikianlah apabila personilnya telah lengkap masing-masing para tamu dipersilahkan untuk cuci tangan lanjut bersantap. Salah seorang dari masing-masing sela tersebut bertugas sebagai tukang pepara (menaikan lauk ke atas gibungan). Demikianlah acara megibung ini berlangsung penuh disiplin. Para pengayah (peladen) yang membawa tambahan air, nasi dll sibuk meladeni para tamu yang sedang bersantap. Acara megibung ini berlangsung sekitar lima belas menit atau lebih. Apabila para tamu telah selesai santap (mereka biasanya bengong saling tunggu) maka tuan rumah atau yang mewakili mempersilahkan untuk cuci tangan lanjut bubaran. Mereka (para tamu) mencari tempat duduk di tempat lain untuk basa basi dengan tuan rumah akhirnya mohon ijin untuk pamitan. Sudah tentu tuan rumah menjawab dengan ucapan terima kasih serta mohon maaf atas segala kekhilafan dan kekurangannya. Dengan demikian nilai sosiologis yang dapat kita petik dari tradisi megibung adalah gotong royong, kebersamaan dan disiplin.

\section{Nilai Psikologis dalam Tradisi "Megibung"}

Megibung penuh dengan tata nilai dan aturan yang khas. Dalam megibung, nasi dalam jumlah banyak ditaruh di atas dulang (alas makan dari tanah liat atau kayu) yang telah dilapisi tamas (anyaman daun kelapa). Namun sekarang acara megibung jarang menggunakan dulang, diganti dengan nampan atau wadah lain yang dialasi daun pisang atau kertas nasi. Gundukan nasi dalam porsi besar ditaruh di atas nampan dan lauk pauk ditaruh dalam wadah khusus. Orang-orang yang makan duduk bersila secara teratur dan membentuk lingkaran.

Satu porsi nasi gibungan (nasi dan lauk pauk) yang dinikmati oleh satu kelompok disebut satu sela. Pada jaman dulu satu sela harus dinikmati oleh delapan orang. Kini satu sela bisa dinikmati oleh kurang dari delapan orang, seperti 8-10 orang. Ketika makan, masing-masing orang dalam satu sela harus mengikuti aturan-aturan tidak tertulis yang telah disepakati bersama.

Megibung biasanya terdiri dari lebih dari satu sela, bahkan puluhan sela. Setiap sela dipimpin oleh pepara, orang yang dipercaya dan ditugasi menuangkan lauk-pauk di atas gundukan nasi secara bertahap. Setiap satu sela biasanya mendapatkan lauk pauk dan sayuran yang terdiri dari pepesan daging, urutan (sosis), sate kablet (lemak), sate pusut (daging isi), sate nyuh (sate kelapa), sate asem (sate isi dan lemak), lawar merah dan putih, sayur daun belimbing, pademara, dan sayur urap.

Orang-orang yang megibung harus mengikuti tata tertib dan aturan makan yang ketat. Sebelum dimakan, nasi diambil dari nampan dengan cara dikepal memakai tangan. Kemudian dilanjutkan dengan mengambil daging dan lauk-pauk lainnya secara teratur. Sisa makanan dari mulut tidak boleh berceceran di atas nampan. Harus dibuang di atas sebidang kecil daun pisang yang telah disediakan untuk masing-masing orang. Air putih untuk minum disediakan di dalam kendi dari tanah liat. Untuk satu sela disediakan dua kendi. Minum air dilakukan dengan nyeret, air diteguk dari ujung kendi sehingga bibir tidak menyentuh kendi. Untuk kepraktisan, kini air kendi diganti dengan air mineral kemasan. Di beberapa tempat, selesai megibung biasanya dilanjutkan dengan acara minum tuak.

Saat megibung tidak boleh bicara dan ketawa keras, berteriak-teriak, bersendawa, bersin, berdahak, meludah, dan kentut. Ketika selesai makan, orang tidak boleh sembarangan meninggalkan tempat. Harus menunggu orang atau sela lain menyelesaikan makannya. Ketika semua orang atau sela telah menyelesaikan makannya, maka pepara mempersilakan orangorang meninggalkan tempat. Makan bersama ini harus diakhiri secara bersama-sama juga.

"Aturan megibung di setiap tempat di Karangasem biasanya berbeda-beda sesuai desa (wilayah), kala (waktu), patra (kondisi) setempat.

Megibung penuh dengan nilai-nilai kebersamaan. Dalam megibung secara umum tidak ada perbedaan jenis kelamin, kasta atau catur warna. Anggota satu sela, misalnya, bisa terdiri laki dan perempuan, atau campuran dari golongan brahmana, ksatrya, wasya dan sudra. Mereka bersama-sama menghadapi bhoga (hidangan) sebagai berkah Hyang Widhi. Nilai kebersamaan ini telah dicanangkan sejak jaman I Gusti Anglurah Ktut Karangasem, dan sudah menjadi tradisi hingga kini, baik di Karangasem maupun Lombok.

"Orang-orang yang tidak terbiasa megibung atau yang fanatik dengan kasta akan susah mengikuti acara makan ini jika kebetulan diundang menghadiri upacara adat atau agama,"

Lalu, bagaimana jika ada orang yang berpenyakit menular atau orang yang dianggap bisa ngeleak (ilmu hitam) ikut megibung dalam satu sela?. Prinsip megibung adalah kebersamaan dan tidak membeda-bedakan orang. "Jadi orang-orang seperti itu sah-sah saja ikut megibung. Namun sekarang biasanya setiap sela diisi oleh orang-orang yang sudah saling mengenal,". 
Jadi nilai psikologis yang dapat diambil dari tradisi "megibung" ini adalah kebersamaan dan sesetaraan dan keteraturan.

\section{Simpulan dan Saran}

Berdasarkan uraian diatas maka dapat disimpulkan bahwa dalam kajian etnopedagogi, tradisi "megibung" memiliki nilai filosofis, antropologis, sosiologis dan psikologis sebagai berikut.

\begin{tabular}{|c|c|c|}
\hline $\begin{array}{l}\text { Kajian } \\
\text { Etnopedagogi }\end{array}$ & Nilai Kearifan Lokal & Keterangan \\
\hline Nilai Filosofis & $\begin{array}{l}\text { "paros sarpanaya, } \\
\text { selunglung } \\
\text { sabayantaka" atau } \\
\text { kebersamaan dalam } \\
\text { suka dan duka. }\end{array}$ & $\begin{array}{l}\text { Nilai filosofis ini sangat penting dalam dunia } \\
\text { pendidikan untuk menciptakan semangat } \\
\text { kesetiakawanan dalam proses pembelajaran } \\
\text { ataupun kehidupan sehari-hari. }\end{array}$ \\
\hline Nilai Antropologis & $\begin{array}{l}\text { kebersamaan, disiplin } \\
\text { dan kekerabatan }\end{array}$ & $\begin{array}{l}\text { Dalam konteks antropologis semangat } \\
\text { kebersamaan, disiplin dan kekerabatan yang } \\
\text { ada pada tradisi "megibung" dapat } \\
\text { menumbuhkan rasa persatuan. }\end{array}$ \\
\hline Nilai Sosiologis & $\begin{array}{lr}\text { gotong } & \text { royong, } \\
\text { kebersamaan } & \text { dan } \\
\text { disiplin } & \end{array}$ & $\begin{array}{l}\text { Secara sosiologis, tradisi "megibung" } \\
\text { mengajarkan kita untuk selalu bekerja sama, } \\
\text { dan taat pada aturan yang ada agar semua } \\
\text { kegiatan yang kita laksanakan dapat } \\
\text { terlaksana dengan baik. }\end{array}$ \\
\hline Nilai Psikologis & $\begin{array}{ll}\text { kebersamaan } & \text { dan } \\
\text { sesetaraan } & \text { dan } \\
\text { keteraturan } & \end{array}$ & $\begin{array}{l}\text { Dalam aspek psikologis, tradisi "megibung" } \\
\text { memberikan kesetaraan (kasta) yang sering } \\
\text { sekali dijadikan pembeda diantara masyarakat } \\
\text { Hindu di Bali. Selain itu "megibung" juga } \\
\text { memberikan rasa kebersamaan dengan tidak } \\
\text { memandang latar belakang dari peserta } \\
\text { megibung itu sendiri dan sudah tentu } \\
\text { keteraturan dalam setiap aktivitas yang ada } \\
\text { didalamnya. }\end{array}$ \\
\hline
\end{tabular}

\section{Daftar Pustaka}

Alwasilah, A. C., Suryadi, K., Tri Karyono. (2009). Etnopedagogi: Landasan Praktek Pendidikan dan Pendidikan Guru. Bandung: Kiblat Buku Utama.

Anonim. 2006. Art and Culture. Diakses tanggal 22 Januari 2017 dari http://www.karangasemtourism.com/art_culture/.

Anonim. 2006. Keberagaman. Diakses tanggal 22 Januari 2017 dari http://balebanjar.com/index.php/content/view/213/109/.

Anonim. 2006. Magibung. Diakses tanggal 22 Januari 2007 dari http://baliwww.com/bali-newsevents/509/.

Anonim. 2007.Karangasem on The Wallace Line. Diakses tanggal 22 Januari 2007 dari http://www.bali-travelnews.com/Batrav/Batrav195/karangasem.htm

Banjar, Kelihan. 2006. Keberagaman. Diakses tanggal 20 Januari 2007 dari http://balebanjar.com.

Geriya, I Wayan. 1997. Pendekatan Partisipasi Masyarakat untuk Menunjang Program Kartadinata, S. (2010). Etnopedagogik: Sebuah Resureksi Ilmu Pendidikan (pedagogik). Makalah disajikan pada 2nd International Seminar 2010 'Practice Pedagogic in Global Education Perspective'. PGSD UPI, Bandung, 17 May, 2010. 
Pelestarian Warisan Budaya. Majalah Dokumentasi Budaya Bali. No. 6/triwulan II/1997. Setiawan, Putu. 2007. Magibung Biu, Tradisi Makan Pisang Bersama. Diakses tanggal 17 Januari 2017 dari http://www.liputan6.com.

Kartawinata, Ade.M.(2011). Merentas Kearifan Lokal Di Tengah Modernisasi dan Tantangan Pelestarian, dalam Nasruddin (2011).Kearifan Lokal Di Tengah Modernisasi. Jakarta: Pusat Penelitian dan Pengembangan Kebudayaan Badan Pengembangan Sumber Daya Kebudayaan dan Pariwisata Kementerian Kebudayaan dan Pariwisata Republik Indonesia. 